\title{
Oxidation Behavior of TP304H in Water Vapor at $590{ }^{\circ} \mathrm{C}$
}

\author{
W. GAO ${ }^{a_{1},}$, J.N. LIU ${ }^{b}$, Z. P. WANG ${ }^{c}$, Y.H. JIN ${ }^{d}$ and Y.H. YAO \\ ${ }^{1}$ School of Material, Northwestern Polytechnical University, China. \\ ${ }^{2}$ School of Materials and Chemical Engineering, Xi'an Technological University, China. \\ agaowei@xatu.edu.cn, bliujiangnan@xpu.edu.cn, cwang_zhengpin@163.com, djinyhua@sohu.com, \\ eyyhong0612@163.com \\ ${ }^{*}$ Corresponding author
}

Keywords: TP304H, High-temperature Steam, Oxidation Dynamic, Oxidation Layer.

\begin{abstract}
Oxidation tests were performed in water vapor at $590{ }^{\circ} \mathrm{C}$ by mass gain to study the oxidation behavior under working conditions of TP304H steel, which is a new alloy steel used for overheaters and reheaters in high-parameter boilers operated in thermal power stations. The microstructure was observed in different oxidation stages by using metallurgic microscopy and scanning electron microcopy. Furthermore, the components of oxidation products were analyzed by EDS.
\end{abstract}

Results showed that the oxidation kinetic curve of TP304H steel was in line with $y=-3.92+$ $2.36 x^{0.18}$ at $590{ }^{\circ} \mathrm{C}$ vapor. The oxidation film consisted of the following two layers: the inner layer was compact, whereas the outer layer was pertusate. Oxide layer thickness gradually increased over time. Oxygen content gradually decreased from the outside toward the center of the oxide layer. Iron content was the lowest in the inner layer. $\mathrm{Cr}$-rich and $\mathrm{Ni}$-rich areas appeared in the inner layer. By contrast, low amounts of $\mathrm{Cr}$ and $\mathrm{Ni}$ are found in the outer layer.

\section{Introduction}

With the development of electric power industry and to improve the thermal power unit steam parameters, explosive leakage accident damage from "four-tube" thermal power boilers (economizer, water wall, superheater, and reheater) has become the main factors that influence the establishment of safe and economic guidelines[1-3]. During operation of thermal power, boilers, four-tube leakage and upward blast accounted for approximately $30 \%$ of the total number of accidents. Numerous reasons cause these explosion and leakage accidents, the most serious of which are caused by corrosion, especially corrosion occurring inside heating tubes. Apart from damage to a major heating surface, this type of accident may also cause personal injuries[4-7]. Under the high temperature and high pressure of water vapor with for extended time periods, the tube interior can produce oxidation film, which is peeled off easily under cold-heat, cycle conditions because of the different coefficients of thermal expansion of the base and the oxidation film. Film stuck to the elbow of tubes could cause plugging pipe accidents and exert a significant impact on the safe and economic operation of power plant boilers. Despite the problem that film formation poses to the industry, no effective means to detect the thickness of oxide films are available. Therefore, research on this issue is relatively backward, and research on the formation mechanism and prevention methods of oxide film is lacking. As a result,the development of electric power industry to larger capacity and high parameters in our country is limited ${ }^{[8,9]}$. TP304H steel, a new type of steels, is used in high-parameter boiler superheater and reheater tubes ${ }^{[10-12]}$. In the present study, we investigated TP304H stainless steel and its oxidation behavior under working conditions to provide basis for the use of the steel in supercritical and ultra supercritical thermal power units. 


\section{Materials and Methods}

The materials used for testing TP304H macrocrystal austenitic stainless steel and components are shown in Table 1 . Samples ( $26 \mathrm{~mm} \times 10 \mathrm{~mm} \times 3 \mathrm{~mm}$ ) obtained from a spare tube in a power plant, were polished, cleaned, degreased, dried at a low temperature, and weighed.

Table 1 Chemical composition of TP304H steel (wt \%)

\begin{tabular}{cccccccc}
\hline $\begin{array}{c}\text { Compone } \\
\text { nt }\end{array}$ & $\mathrm{C}$ & $\mathrm{Mn}$ & $\mathrm{S}$ & $\mathrm{P}$ & $\mathrm{Si}$ & $\mathrm{Cr}$ & $\mathrm{Ni}$ \\
\hline Content & 0.10 & $\leq 2.00$ & $\leq 0.040$ & $\leq 0.030$ & $\leq 0.75$ & 18.00 & 9.00 \\
\hline
\end{tabular}

In this test, pressure of the device was slightly higher than atmospheric pressure (about 0.18 Mpa), double-distilled water was used, and the total time of oxidation was $1000 \mathrm{~h}$. At oxidation time points of 100, 200, 410,650, $1000 \mathrm{~h}$, the samples were taken out for weighing and recording. The dynamic oxidation weight-time curve was plotted using origin software for data analysis.

An FEI Quanta400 scanning electron microscope (SEM) was used to observe the TP304H surface and the microstructure of fracture after oxidation, and the composition of oxidation products were analyzed using Oxford Energy Dispersive Spectrometer (EDS).

\section{Testing Results and Analysis}

The oxidation kinetics of the TP304H stainless steel under water-vapor condition follows a parabolic rate law ( $\mathrm{y}=-3.92+2.36 \mathrm{x} 0.18$, $\mathrm{x}$ is time and $\mathrm{y}$ is oxide weight unit area.) at $590{ }^{\circ} \mathrm{C}$ for durations of up to $1000 \mathrm{~h}$. The kinetic curve of oxidation is shown in Fig. 1. The oxidation rate is extremely rapid at $100 \mathrm{~h}$, after which the rate slowed down. Given that the surface of specimen was in contact with water vapor directly in the initial stage of oxidation, the matrix metal ions and oxygen ions in water vapor quickly react to the oxide attached to the surface of the specimen. The reaction can only rely on atom diffusion when the growth of oxide film covers the whole substrate surface, and then the oxide formation rate becomes slow. With the gradual thickening of the oxide film, diffusion becomes increasing difficult, and the oxidation rate gradually decreases.

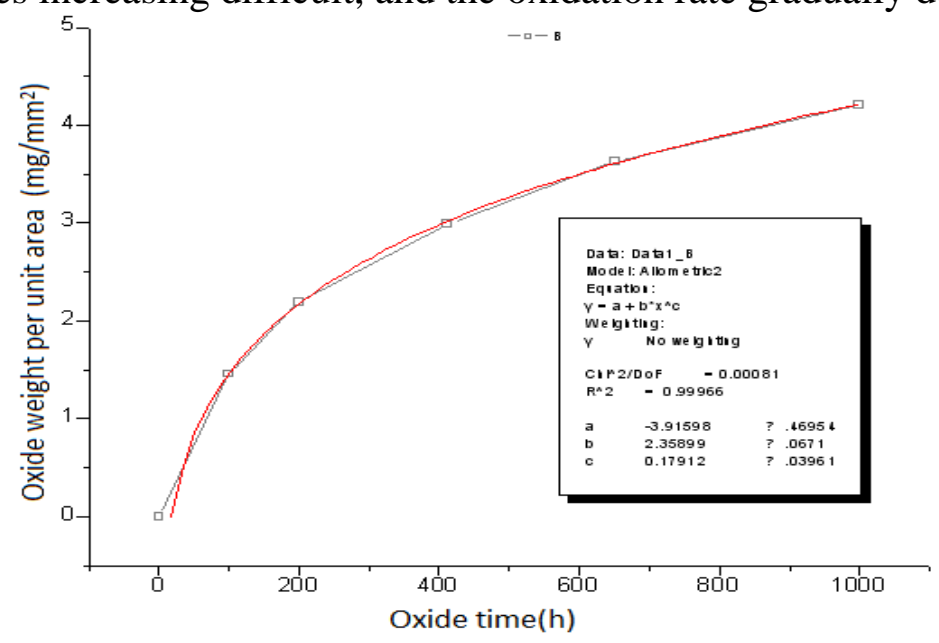

Figure1. Oxidation kinetic curve of TP304H steel under $590^{\circ} \mathrm{C}$ vapor

The images in Fig. 2 show TP304H steel surface micro-morphology under water vapor at $590^{\circ} \mathrm{C}$ after different oxidation times, where (a), (b), (c), (d), and (e) correspond to oxidation at 100, 200, 410, 650 and $1000 \mathrm{~h}$, respectively. At $100 \mathrm{~h}$, the crystal of the oxide film surface is plate and columnar crystal nucleus growth and large holes were observed on the plate oxide film. Evident growth of the oxide crystal and the columnar crystal nucleus on the crystal appeared up to $200 \mathrm{~h}$. After 410h, the surface oxide with the small crystal nucleus and several holes has become dense, and crystal grain grew. Compared with the state after $410 \mathrm{~h}$, crystal longitudinal growth, evident 
inverse spinel-type structure, unchanged crystal grain size was observed at $650 \mathrm{~h}$, but more holes are produced in the middle of the crystal. The oxide-connected pieces and the holes were smaller in the crystal after $1000 \mathrm{~h}$ of oxidation. As seen in Fig.3, with the extension of oxidation time, the oxidation layer surface shows a columnar growth. First, the formed holes on the surface of the oxide film become smaller and fewer, until the holes disappeared. In addition, more columnar crystals appear until a new surface is formed.

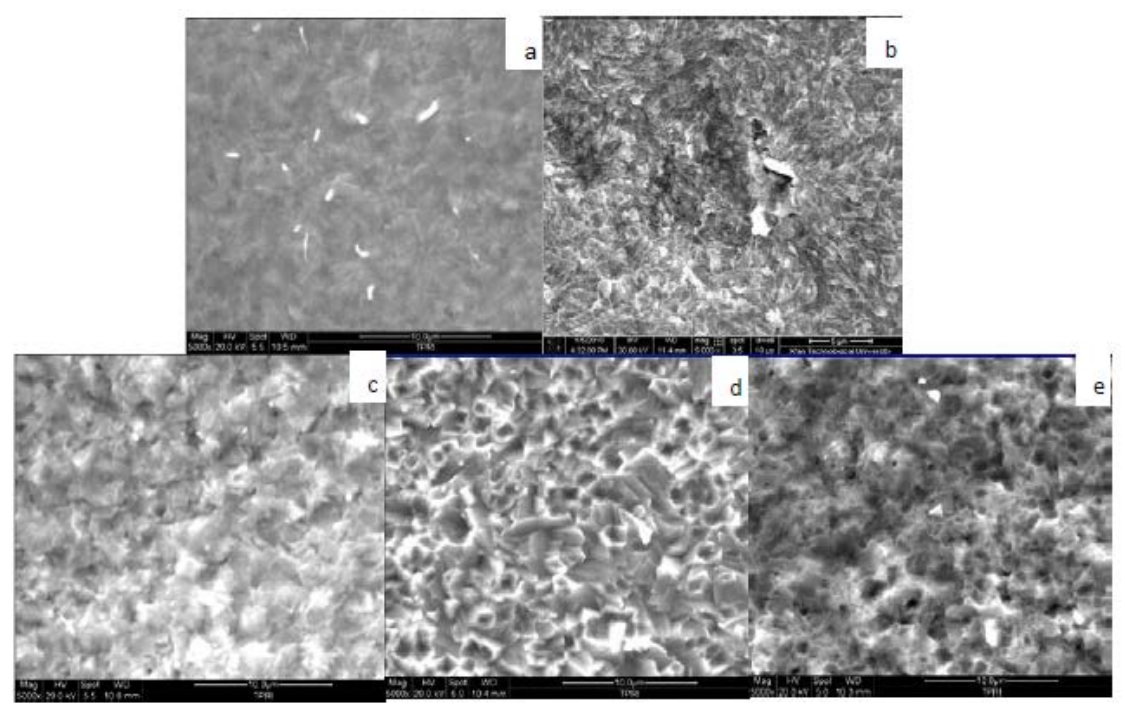

Figure2. Surface microstructure of the oxide film on TP304H steel under $590^{\circ} \mathrm{C}$ vapors.

The images in Fig. 3 show the TP304H steel microstructure of the oxide film section in water vapor at $590{ }^{\circ} \mathrm{C}$, where, the (a), (b), (c), (d), and (e) denotes oxidation after 100, 200, 410, 650, and $1000 \mathrm{~h}$. Based on the graph, different oxidation times result in oxide film formation both inside and outside in a two-layer structure, in which the combination between layers present a smooth surface. A black point on the inner layer and a hole on the outer layer of oxide film are observed, and the section of oxide film grows rapidly. The oxide film with uniform thickness gradually increased with the increasing oxidation time. Film thickness gradually increased as well. As shown in Table 2, the total thickness of the oxidation layer from $100 \mathrm{~h}$ to $1000 \mathrm{~h}$ increased from $11.6 \mu \mathrm{m}$ to $39.8 \mu \mathrm{m}$. Notably, the inner film layer grows faster than the outer layer.

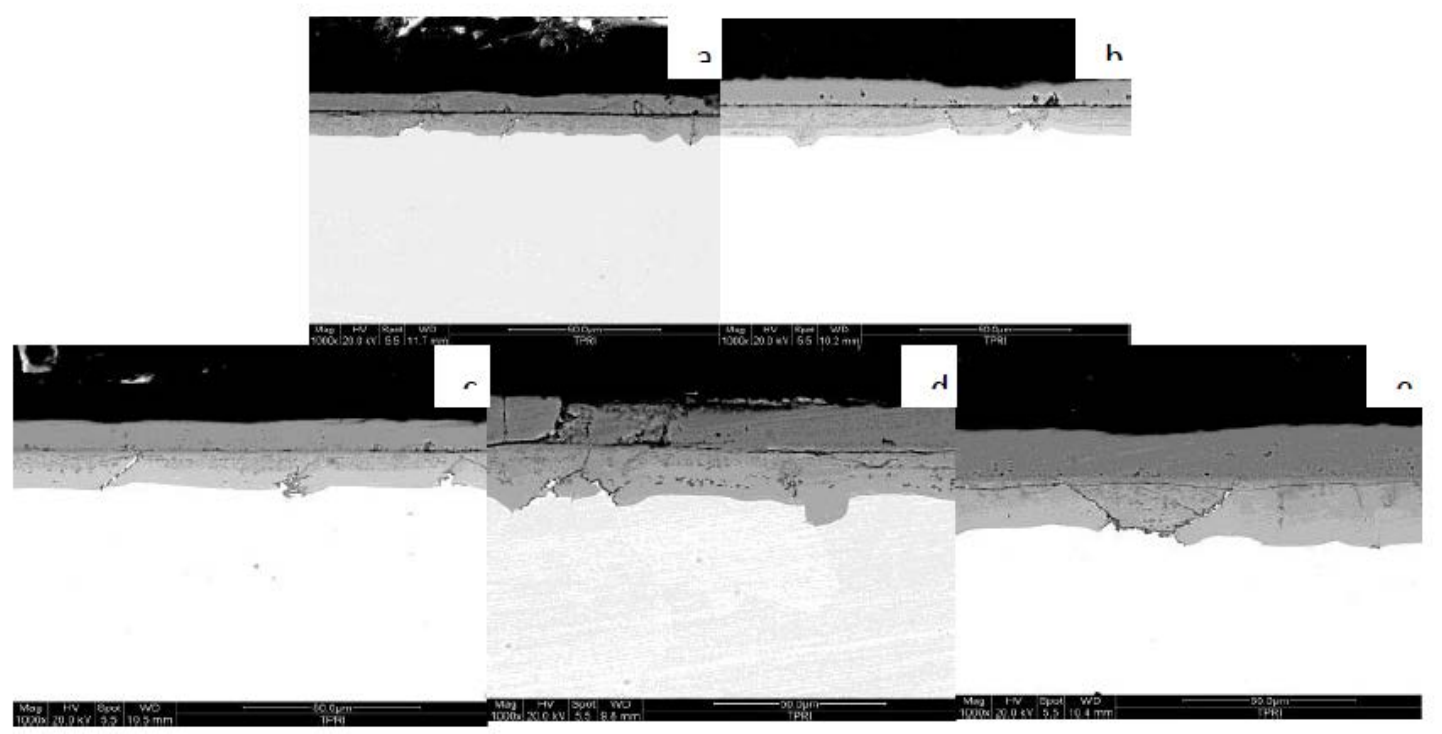

Figure3. Microstructure of TP304H steel oxide film section under $590{ }^{\circ} \mathrm{C}$ vapor 
Table 2 Thickness of TP304H steel oxide film under $590{ }^{\circ} \mathrm{C}$ vapor

\begin{tabular}{|c|c|c|c|c|c|}
\hline Location & $100 \mathrm{~h}$ & $200 \mathrm{~h}$ & $410 \mathrm{~h}$ & $650 \mathrm{~h}$ & $1000 \mathrm{~h}$ \\
\hline Outer layer $/ \mu \mathrm{m}$ & 5.36 & 7 & 9.87 & 14.6 & 18 \\
\hline Inner layer $\mu \mathrm{m}$ & 6.24 & 7.2 & 13.2 & 18.8 & 21.8 \\
\hline
\end{tabular}

The images in Fig. 4 and Fig. 5 respectively show the EDS results of the TP304H steel oxidation cross section, after 410 and $1000 \mathrm{~h}$. Table 3 and Table 4 respectively show the content of alloy elements. According to Fig. 4, Fig. 5, Table 3, and Table 4, the O element content gradually decreases from the film's outer layer to the inner layer, and substrate oxygen content is at the lowest on the interface of the inner layer. Fe content was the highest in the matrix and outer layer of the oxide film, with a minimum content in the inner layer. Near the substrate, as well as the inner and out layer interface, Fe content is less than that in the matrix, but its content is higher than that in the inner layer of oxide film. This distribution is explained by the outward diffusion of surface Fe with oxygen during the initial stage of oxidation of the specimen surface from to the outer layer to form the outer layer of oxide film. Then, the outward diffusion of Fe from matrix is impeded by oxide film. Thus, the loss of Fe from the inner oxide film layer is not compensated. The Cr content in the outer oxide film layer is the lowest, closely approximating 0 , whereas that in the inner layer is the highest. Moreover, up to 650 and 1000 h, a Cr-rich area emerges in the grain boundaries of the Cr matrix. The highest content of $\mathrm{Cr}$ in this area reached $36.37 \mathrm{wt} \%$, which is markedly higher than the content in the matrix. The lowest elemental Ni content was observed in the outer layer of the oxide film, whereas the highest Ni content was observed in the inner layer. A Ni-rich area emerges in the inner layer and the inside of the matrix interface, and the highest $\mathrm{Ni}$ content in the area reached 15.18 wt. \%. However, the $\mathrm{Cr}$ content in areas with high $\mathrm{Ni}$ content is low, and conversely, the Ni content in areas with high $\mathrm{Cr}$ content is also low.

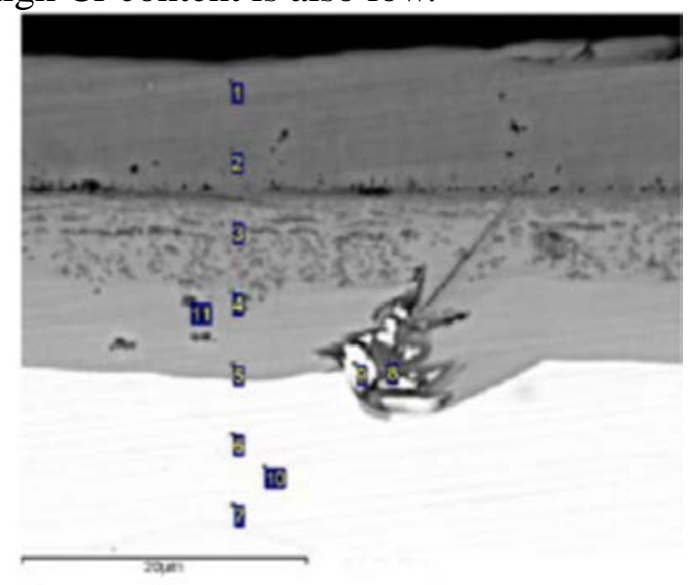

Figure4. Energy spectrum analysis of TP304H after 410 h oxidation 
Table 3 Component of TP304H after 410 h oxidation (wt.\%).

\begin{tabular}{|c|c|c|c|c|c|c|c|}
\hline Spectra & $\mathrm{O}$ & $\mathrm{Si}$ & $\mathrm{Cr}$ & $\mathrm{Mn}$ & $\mathrm{Fe}$ & $\mathrm{Ni}$ & Mo \\
\hline 1 & 31.90 & 0.49 & 0.68 & 0.48 & 66.45 & & \\
\hline 2 & 29.21 & 0.74 & 1.33 & & 68.73 & & \\
\hline 3 & 23.09 & 0.58 & 24.43 & 1.31 & 39.31 & 10.70 & 0.59 \\
\hline 4 & 20.47 & 0.76 & 23.70 & 2.08 & 40.47 & 11.57 & 0.95 \\
\hline 5 & 17.64 & 0.41 & 23.65 & 2.09 & 42.30 & 13.06 & 0.85 \\
\hline 6 & & 0.47 & 19.32 & 1.87 & 70.31 & 7.55 & 0.47 \\
\hline 7 & & 0.39 & 19.27 & 1.53 & 70.49 & 7.93 & 0.40 \\
\hline 8 & 27.47 & 0.67 & 35.06 & 3.29 & 28.35 & 4.31 & 0.85 \\
\hline 9 & & 0.06 & 11.69 & 1.17 & 71.13 & 15.18 & 0.76 \\
\hline 10 & & 0.43 & 19.21 & 1.82 & 69.83 & 8.00 & 0.72 \\
\hline 11 & 21.82 & 0.59 & 26.21 & 2.23 & 38.86 & 9.58 & 0.70 \\
\hline
\end{tabular}

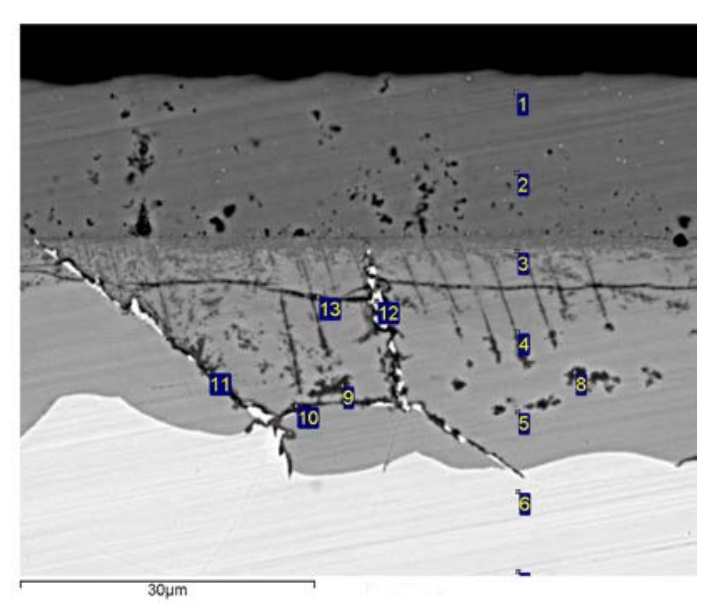

Figure5. Energy spectrum analysis of TP304H after 1000 h oxidation

Table 4 Component of TP304H after 1000 h oxidation (wt.\%).

\begin{tabular}{|c|c|c|c|c|c|c|c|}
\hline Spectra & $\mathrm{O}$ & $\mathrm{Si}$ & $\mathrm{Cr}$ & $\mathrm{Mn}$ & $\mathrm{Fe}$ & $\mathrm{Ni}$ & $\mathrm{Mo}$ \\
\hline 1 & 31.42 & 0.19 & 0.44 & 0.59 & 67.36 & & \\
\hline 2 & 29.12 & 0.46 & 0.79 & & 69.63 & & \\
\hline 3 & 25.44 & 0.59 & 25.27 & 1.11 & 38.58 & 8.38 & 0.62 \\
\hline 4 & 21.35 & 0.62 & 25.57 & 2.62 & 40.10 & 8.73 & 1.00 \\
\hline 5 & 17.27 & 0.75 & 23.04 & 2.28 & 42.96 & 12.86 & 0.85 \\
\hline 6 & & 0.45 & 19.52 & 1.77 & 70.01 & 7.66 & 0.59 \\
\hline 7 & & 0.50 & 19.31 & 1.71 & 69.92 & 7.93 & 0.63 \\
\hline 8 & 23.27 & 0.79 & 31.21 & 3.11 & 35.40 & 5.40 & 0.83 \\
\hline 9 & 25.36 & 0.66 & 34.44 & 2.87 & 31.79 & 3.90 & 0.99 \\
\hline 10 & 23.20 & 0.74 & 32.66 & 2.95 & 33.25 & 6.55 & 0.64 \\
\hline 11 & 24.79 & 0.97 & 36.37 & 3.60 & 29.50 & 4.06 & 0.73 \\
\hline 12 & 11.08 & 0.26 & 16.07 & 1.07 & 53.69 & 17.48 & 0.35 \\
\hline 13 & 20.76 & 0.51 & 27.27 & 2.63 & 37.92 & 10.03 & 0.89 \\
\hline
\end{tabular}




\section{Conclusions}

The oxidation kinetics of the TP304H stainless steel under water-vapor condition follows a parabolic rate law $(\mathrm{y}=-3.92+2.36 \mathrm{x} 0.18)$ at $590^{\circ} \mathrm{C}$ for duration of up to $1000 \mathrm{~h}$.

The constructed oxidation film is composed of two layers, namely, the inner and outer layers, with relatively uniform thickness. However, the thickness of the oxidation layer gradually increases over time. The inner layer becomes relatively dense, and oxidation films in certain sections grow fast. In addition, some holes that formed a columnar pattern were found in the outer layer. The formed holes on the surface of the oxide film first became smaller, and then became fewer until the holes disappeared. Moreover, more columnar crystals appeared until a new surface was formed.

The content of oxygen in the oxidation layer gradually decreases from the outside to the inside. Fe element is the lowest in the inner layer and highest in the outer layer and the substrate. In addition, the contents of $\mathrm{Cr}$ and $\mathrm{Ni}$ elements in the inner layer are higher than that in the substrate, resulting in the emergence of Cr-rich and Ni-rich regions. However, low $\mathrm{Cr}$ and Ni contents are observed in the outer layer.

\section{Acknowledgements}

This research was financially supported by the National Natural Science Foundation of China (Contract No.51371132) and the Key Laboratory Project of the Education Department of Shaanxi Province (Contract No. 14JS031).

\section{References}

[1] A. Saad Abou-elazm, I. El Mahallawi,R. Abdel-karim, R. Rashad, 'Failure investigation of secondary super-heater tubes in a power boiler’,Engineering Failure Analysis 16 (2009) 433-448.

[2] ZHU Jian-chen, 'Analysis on the forming and falling-off problem of oxides on the austenitic stainless steel pipe[D]', North China electric power university(Hebei),2009.(in Chinese)

[3] WANG Zheng-pin, ZHANG Lu, LIU Jiang-nan, etc, 'Failure analysis of high temperature steam oxidation of T22 and T91 tubes for power station [J]', Foundry technology, 2004, 7(25): 523-525. (in Chinese)

[4] J. Salehi, R. Sayyari, H.R. Mohajerani, ' Failure analysis of conversion reactor drum by metal dusting’, Engineering Failure Analysis 24 (2012) 33-37.

[5] M.M. Prieto, I. Sua'rez , F.J. Ferna'ndez , H. Sa'nchez , C. Viescas, 'Application of a thermal model to a power plant reheater with irregular tube temperatures', Applied Thermal Engineering 27 (2007) 185-193.

[6] ZHANG Yong-jian, 'Oxidation and heat transfer analysis of heat resisting stainless steel in high temperature and high pressure water vapor[D]', National university of defense technology,2006. (in Chinese)

[7] Yan Gao, Chunlei Zhang, Xiahua Xiong, Zhijun Zheng, Min Zhu, 'Intergranular corrosion susceptibility of a novel Super304H stainless steel’, Engineering Failure Analysis 24 (2012) 26-32.

[8] J. Purbolaksono, A. Khinani, A.Z. Rashid, A.A. Ali, N.F. Nordin, 'Prediction of oxide scale growth in superheater and reheater tubes’, Corrosion Science 51 (2009) 1022-1029.

[9] TANG Hai-ning, 'Comprehensive analysis of the oxide-scale exfoliation in large capacity boiler of power [D]', Southeast university,2006. (in Chinese)

[10] Indrani Sena, E. Amankwaha, N.S. Kumara, E. Fleuryc, K. Oh-ishid, K. Honod, U. Ramamurtya, 'Microstructure and mechanical properties of annealed SUS 304H austenitic stainless steel with copperMaterials’, Science and Engineering A 528 (2011) 4491-4499. 
[11] ZHOU Ai-sheng, YUE Zeng-wu, ZHAO Yong-ning, 'Analysisi of the changing procedure of TP304H steel at high temperature [J]’, Shandong electric power, 2000, (5). (In Chinese)

[12] Chunwen Sun, Rob Hui, Wei Qu, Sing Yick, 'Progress in corrosion resistant materials for supercritical water reactors’,Corrosion Science 51 (2009) 2508-2523. 